\title{
Performance Analysis of a Constructed Dual Axis Solar Tracker
}

\author{
$\begin{array}{lll}\text { Y. K. Sanusi } & 1 & \text { T. B. Asafa } \\ & \text { A.A. Kazeem }\end{array}$ \\ 1.Department of Pure and Applied Physics, Faculty of Pure and Applied Sciences, Ladoke Akintola University \\ of Technology, PMB 4000 Ogbomoso Nigeria \\ 2.Department of Mechanical Engineering, Faculty of Engineering and Technology, Ladoke Akintola University \\ of Technology, PMB 4000 Ogbomoso Nigeria
}

\begin{abstract}
A major drawback to photovoltaic system is the fact that solar cells become useless at night. In the quest to overcome this, use of batteries, converters, backup generator and addition of extra panels at higher cost to PV grid have been proposed but the performance of the system with integration of the said components is still very much dependent how much solar energy directly reach the solar cell surface. A feasible approach to achieve this is solar tracking. In this study, performance evaluation of a constructed dual axis solar tracker integrated PV system was carried out for five weeks and compared with that of a flat fixed PV system installed at Ogbomoso, Nigeria $\left(8^{\circ} 08^{\prime}\right.$ $\mathrm{N}, 4^{\circ} 16^{\prime} \mathrm{E}$ ). It was discovered that the power and performance of dual axis system obtained averagely was 62.91 W compared to that of flat fixed PV System which was $47.88 \mathrm{~W}$ thereby improving the power output by $31.4 \%$. Keywords: Solar Energy, Dual Axis System, Photovoltaic, Performance, Tropical region, Nigeria.
\end{abstract}

DOI: $10.7176 /$ APTA/75-01

\subsection{Introduction}

There is increase in beam radiation (the solar component converted into electricity) that incident on the solar panel when the sun's position is normal to the panel's surface [1]. Nature does not keep the earth stationary relative to the sun so that its position remains normal to panel's surface all day. Hence varying values of beam radiation is absorbed for conversion [2]. The generation of electricity cannot be done efficiently throughout the day even if the solar panel is tilted. Therefore, a solar panel which can automatically tilt according to the sun's position is necessary such that the panels are always perpendicular to the solar energy radiated by the sun. [3]

It has been estimated that the use of a tracking system, over a fixed system, can increase the power output by $30 \%-60 \%$ [4]. The increase is significant enough to make tracking a viable preposition despite of the enhancement in system cost. Tracking system can be single as shown in Figure 1(a) or dual axis. Automatic single axis solar tracking system is widely used but the position of the sun is not the same in each season as shown in Figure 1(b). Therefore, this tracking system cannot generate the electricity to its full potential for all year long [5]. This called for dual axis tracking system such that the sun's position can be effectively tracked at all seasons. A microcontroller tracking system is made up of two segments, the mechanical and electronics/electrical segments. The mechanical system consists of the DC motors, worm gears and the frame that housed the entire system. The electrical \& electronic system consists of PV sensor, a comparator circuit and a microcontroller [6]. These segments can be connected to computer by software to accumulate data and analyzed.

Popularly used dual axis tracking system employs linear IC devices but it is plagued with limited flexibility and low efficiency. Microcontroller tracking PV system on the other hand has advantages such as fast data processing, flexibility and easy accessibility [7]. For this study, microcontroller developed by micro chip company, number 16F877 was employed. The tracking axes of the mechanical system are made perpendicular to each other with $180^{\circ}$ rotation and parallel to the earth surface.

(a)

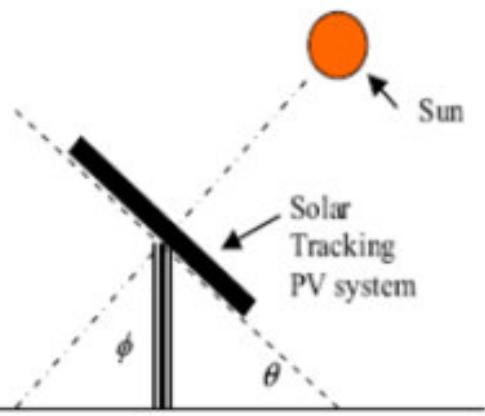

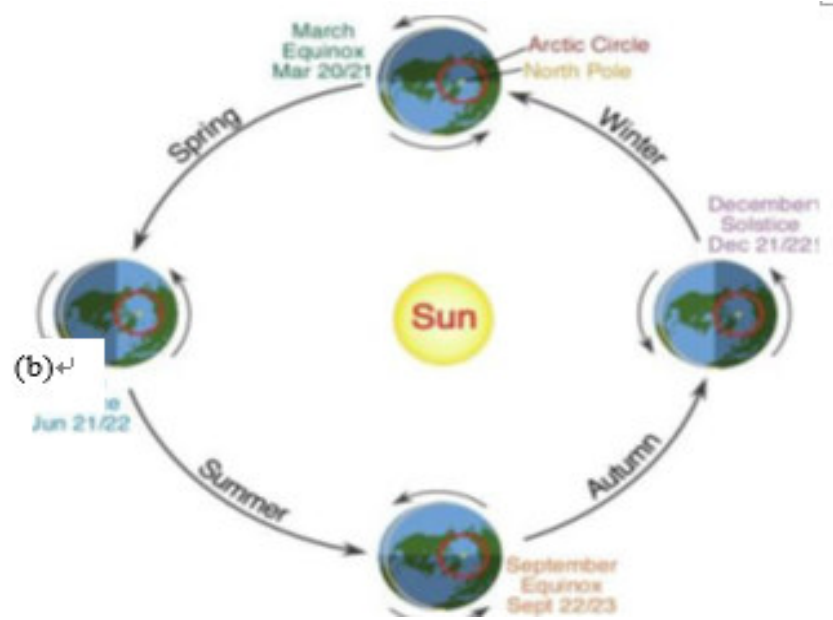

Fig 1.1: (a) Single Axis Solar Tracking PV System; (b) Sun's Position Relative to Earth in Different Seasons; 


\subsection{SYSTEM DESIGN}

As part of the mechanical system, two different stands of the same height were constructed and installed at Ogbomoso, Nigeria. ( $\left.8^{\circ} 08^{\prime} \mathrm{N}, 4^{\circ} 16^{\prime} \mathrm{E}\right)$ with one of them integrated with the tracking system. The rectangular solar panel frame and another outer frame can rotate clockwisely or couterclockwisely around perpendicular horizontal axes as shown in Plate 2.1. The other is without tracking system with its solar panel frame flat and fixed. For the tracker integrated system, the closed-loop system is as shown in the block-diagram in Figure 2.1.

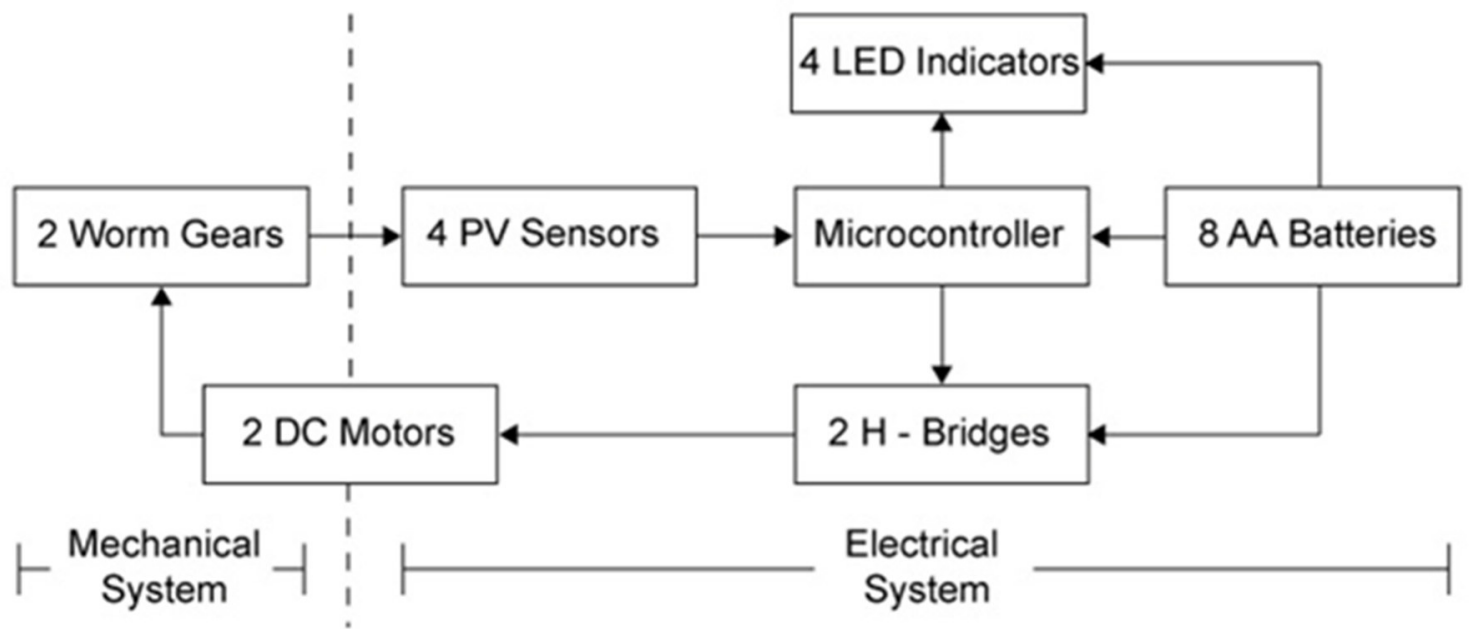

Figure 2.1: Block-diagram of the tracking system.

The electrical system consists of four PV sensors which provide feedback to a microcontroller. This microcontroller processes the sensor input and feed the output to two H-Bridges and four LED indicators. The entire electrical system is powered by a $12 \mathrm{~V}$ source, which consists of $8 \mathrm{AA}$ batteries. The H-bridge controls the two DC motors that are responsible for automatic biaxial repositioning of the solar panel such that its surface remains normal to sun position. The mechanical system also contains two worm gear assemblies that adjust the PV sensors. A solar panel was mounted on each of the panel frames of the two systems and connected to ammeters and voltmeters for current-voltage output measurements. Simultaneous hourly I-V data were obtained for both systems for five weeks (January $3^{\text {rd }}$ to $30^{\text {th }}, 2016$ ). The average hourly power output for both systems were determined for seven days of each week and the results analyzed.

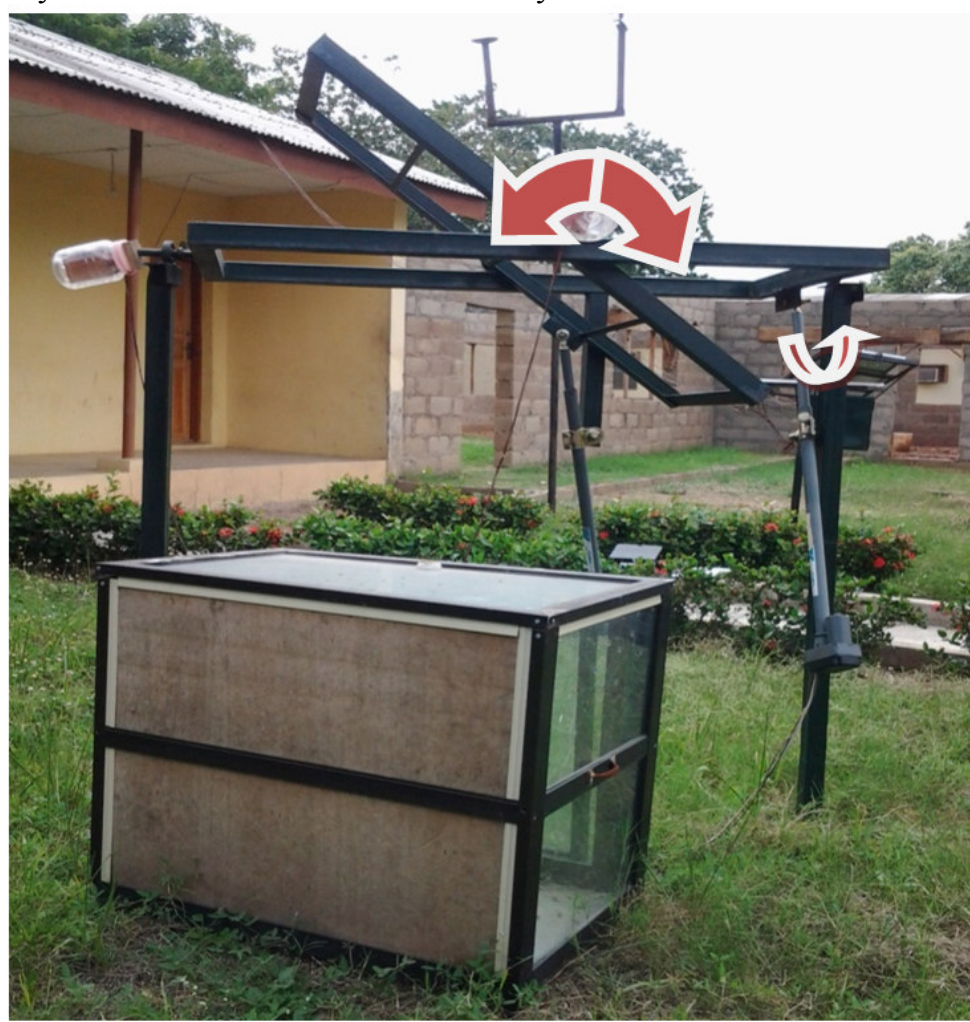

Plate 2.1: Side View of the Constructed Dual Axis Solar Tracker 
The time at the point of taking readings from the solar panel was assumed to correspond to the sun's position so that at midnight the sun is exactly behind the earth at $180^{\circ}$ to the zenith and that at noon, the sun is directly between the east and west horizons or $0^{\circ}$ to the zenith.

\section{RESULTS AND DISCUSSION}

The results obtained and summarily represented in Figure 3.1 shows that generally, the power output of the dual axis photovoltaic system and that of flat fixed system increases with the hour of the day, and the maximum power recorded around 12.00noon to $1.00 \mathrm{pm}$ every day, that is when the sun is at earth zenith. This is when maximum solar intensity reaches the earth surface. Noticeably, the nearly same power output recorded for both systems at zenith interval is attributed to the fact that both system had their panels parallel to the earth as the dual axis reposition its panel such that sun's position is normal to its surface. So, both systems record the nearly the same maximum power outputs at zenith. But after this time range the power output for both system started to decrease gradually till minimum value was recorded around $6.00 \mathrm{pm}$. This is the time when the solar intensity received on the earth surface reduces to lower values as the sun sets. The hourly power output recorded for the dual axis PV system was higher than that recorded for the flat fixed PV system at all hours of the days except the zenith time as shown in Figure 3.1(a)-(e) so also the average power output for the weeks as shown in Figure 3.1 (f). This shows that the dual axis photovoltaic system is an effective approach to maximize the power output of PV system.
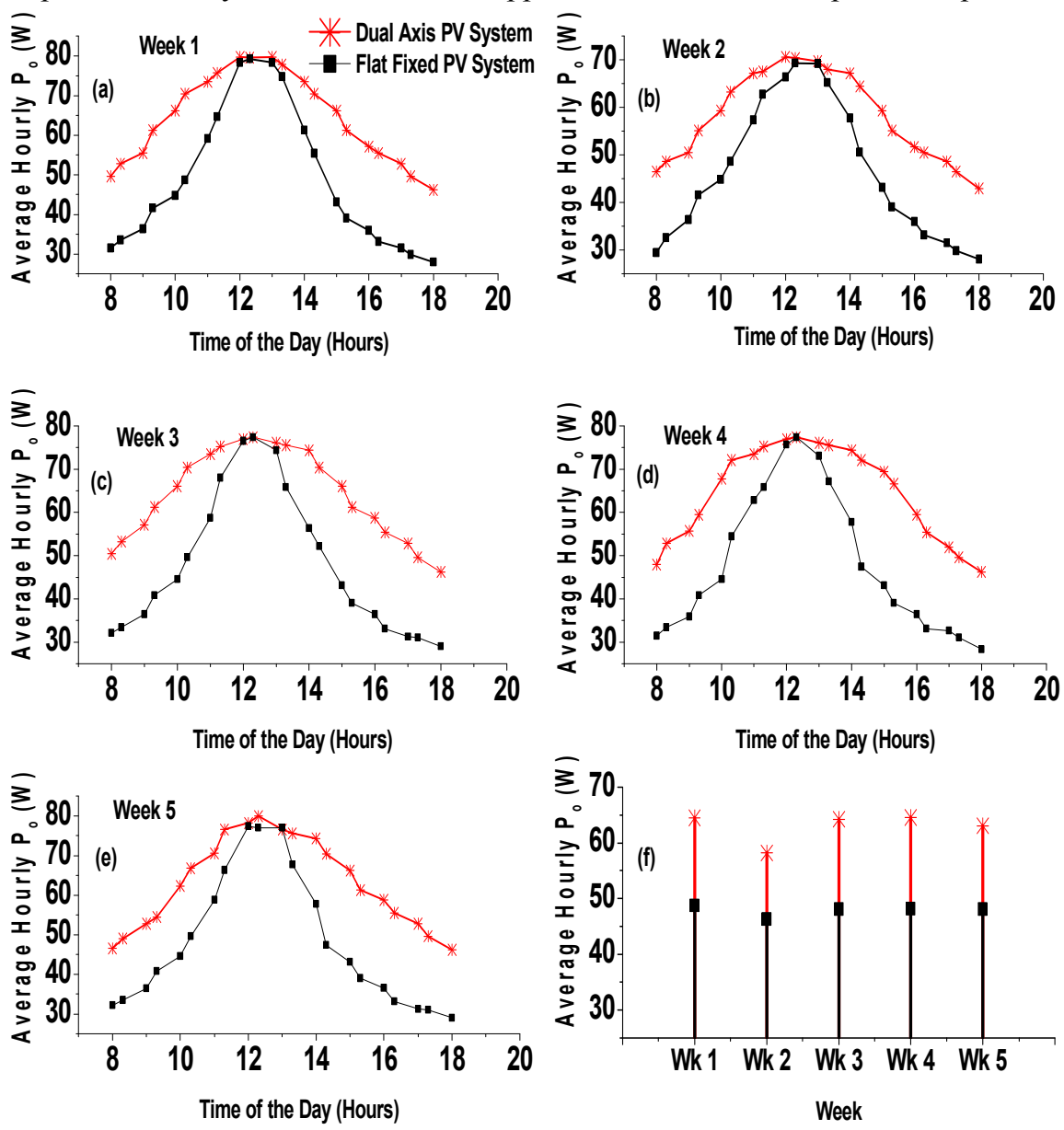

Figure 3.1: (a)-(e) Hourly Power Output for Day 1-5; (f) Average Power Output for the Days

\section{CONCLUSION}

Dual-axis tracking PV system had been successfully constructed and investigated under climate conditions of Ogbomosho, Nigeria $\left(8^{\circ} 08^{\prime} \mathrm{N}, 4^{\circ} 16^{\prime} \mathrm{E}\right)$. The results of the analysis had shown that the dual-axis tracking system provides the better performance when compared with flat fixed photovoltaic system if they are installed in the same geographical location.

\section{REFERENCES}

1. P. Mialhe, S. Mouhamed, A. Haydar, The solar cell Output Power Dependence on the Angle of Incident Radiation, Science Direct: Renewable Energy 1(3-4): 519-521 
2. Julian, C. C. (2011)" Physics of Solar Energy" John Wiley \& Sons, Inc., Hoboken, New Jersey, ISBN 978-0470-64780-6

3. Alberto Dolara, Francesco Grimaccia, Sonia Leva, Marco Mussetta, Roberto Faranda, and Moris Gualdoni, "Performance Analysis of a Single-Axis Tracking PV System", IEEE Journal of Photovoltaics, Vol.2, No.4, October 2012.

4. Francisco D., Pedro D.G. and Luis C.G., " Two axis solar tracker based on solar maps, controlled by a low-power microcontroller "proceeding of the international conference on renewable energies and power quality .Granda (spain), 23rd to $25^{\text {th }}$ March, 2010

5. M. Serhan and L. El-Chaar, "Two Axes Sun Tracking System: Comparison with a fixed system", International Conference on Renewable Energies and Power Quality (ICREPQ’10), March 2010.

6. Kais I. Abdul-lateef, “A Low cost single-axis sun tracking system using PIC microcontroller”, Diyala Journal of Engineering Sciences, Vol. 05, No. 01, pp.65-78, June 2012.

7. Wongsunthornchai, N., and C. Limpornjitwilai, 2001. Learn and Practice with Microcontroller. Innovative Experiment, Bangkok. 